\title{
Characterization of Human Thymic Lymphocytes Forming Rosettes with Stromal Gells
}

\author{
Shigeaki Nonoyama* $\dagger$, Masayuki Nakayama $\dagger$, Jun \\ Abe $\dagger$, Takao Kohsaka $\dagger$, Noboru Kobayashi $\dagger$ and \\ JUN-ICHI YATA* \\ *Department of Pediatrics, School of Medicine, Tokyo \\ Medical and Dental University, Tokyo 113, and \\ $\dagger$ Department of Immunology, National Children's Medical \\ Research Center, Tokyo 154
}

\begin{abstract}
Nonoyama, S., Nakayama, M., Abe, J., Kohsaka, T., Kobayashi, N. and Yata, J. Characterization of Human Thymic Lymphocytes Forming Rosettes with Stromal Cells. Tohoku J. Exp. Med., 1992, 168 (3), 467-474_- The interaction of thymic lymphocytes and stromal cells is believed to be important for $\mathrm{T}$ cell development in thymus. In this study, thymic rosettes (TR), which are cell-cell complexes of thymic lymphocytes and stromal cells, were isolated from human thymic tissue, and were characterized. Treating human thymus with collagenase in mild condition, human TR were successfully isolated. Subsequently, TR were purified by the $1 \mathrm{G}$ sedimentation method. Human TR consisted of a stromal cell in center surrounded by lymphocytes. The stromal cells were positive for CD14, CD11b, and HLA-DR but negative for thymic epithelial cell specific mAb, UH-1, suggesting that they are macrophage/dendritic cells. The lymphocytes which formed TR (TRL) were mainly double positive $(\mathrm{CD} 4+\mathrm{CD} 8+)$ and $\mathrm{CD} 1+$ cells, and few of them expressed bright CD3, indicating that TRL are in the intermediate maturation stage. TRL expressed activation markers (Tal and HLA-DR) in a significantly higher percentage of cells than did unselected thymocytes. Blocking test revealed that CD11a and CD2 are involved in the binding of TRL and the stromal cells as adhesion molecules.—adhesion molecule; $\mathrm{T}$ cell differentiation; human thymic rosettes
\end{abstract}

Stromal cells in the thymus are known to play important roles in $\mathrm{T}$ cell differentiation. They produce several growth factors, which are essential for immature $\mathrm{T}$ cells to proliferate and differentiate into mature $\mathrm{T}$ cells (Le et al. 1987 ; Murray et al. 1989). In addition, immature $\mathrm{T}$ cells are known to bind to stromal cells in vitro, and thymic $\mathrm{T}$ cells are known to be activated through the binding process (Denning et al. 1987). It has been also reported that the self antigens are presented by stromal cells (Lorenz and Allen 1989), suggesting that recognition of self antigen by $\mathrm{T}$ cells is educated by stromal cells. Thus, binding to stromal cells is considered to a be important process for immature $\mathrm{T}$ cells to

Received November 13, 1991 ; revision accepted for publication October 7, 1992. 
differentiate into mature $\mathrm{T}$ cells.

The actual cell cell binding in vivo has been demonstrated by isolating cell cell complex between stromal cells and thymic lymphocytes (thymic rosette (TR)) (Kyewski et al. 1982) from murine thymi. These complexes are considered to represent a in vivo thymic microenvironment, in which immature $\mathrm{T}$ cells communicate with stromal cells.

However, the similar cell-cell complexes have not been demonstrated in human thymus. This is probably because a method to isolate them has not been established yet. The method used in murine system fails to isolate human TR. In this study, we modified the method and successfully isolated human TR. We report the characterization of human thymic rosettes.

\section{Materials and Methods}

\section{Isolation of human $T R$}

Human thymic tissues removed from children during cardiovascular surgery for congenital heart disease were used. The thymus tissue was gently teased, and digested by $100 \mathrm{U} /$ $\mathrm{ml}$ of collagenase (Boeringer-Mannheim, FRG) at $4^{\circ} \mathrm{C}$ for $30 \mathrm{~min}$. Thus obtained cells contained TR. TR were purified by the $1 \mathrm{G}$ sedimentation method described elsewhere (Wekerle et al. 1980). Repeating the $1 G$ sedimentation method five times, TR were obtained in high purity.

\section{Surface marker analysis}

Surface marker expression of TRL was analyzed by flowcytometer. TR were separated into free lymphoid cells (thymic rosette lymphocytes, TRL) and stromal cells by gently pipetting them in phosphate buffered saline (PBS) at $37^{\circ} \mathrm{C}$. The contamination of lymphocytes other than TRL was less than $1 \%$ at this period. Cells were stained by the direct immunofluorescence method, using the following $\mathrm{mAb}$ : anti-T3-FITC (CD3), antiT4-PE (CD4), anti-T8-FITC (CD8), anti-I2-FITC (anti-HLA-DR), and anti-Ta1-PE (CD26). All mAbs were purchased from Coulter (Hialeah, FL, USA). The stained cells were analyzed with an EPICS 753 flowcytometer (Coulter). The cells to be analyzed were gated only for the lymphoid cells.

To analyze surface marker expression of stromal cells, immunomagnetic beads were used. Human TR and monocytes were cultured with human IgG at $4^{\circ}$ for $15 \mathrm{~min}$ to block Fc receptor. Monocytes were obtained from human PBMC by adhesion to plastic wall. Cells were then cultured with various kind of $\mathrm{mAb}$ at $4^{\circ}$ for $15 \mathrm{~min}$. After washing with PBS containing $1 \%$ FCS, cells were incubated with immunomagnetic beads coated with sheep anti mouse IgG (Dynal, Great Neck, NY, USA) at $4^{\circ}$ for 15 min. Numbers of the beads attached to the cells were counted under a microscope. If more than three beads were attached, the cell was considered to be positive for the cultured mAb. Twenty human TR were counted for each mAb. B1 (CD20), My4 (CD14), and Mo1 (CD11b) monoclonal antibodies were purchased from Coulter. The anti-UH-1 IgG mAb, specific for human thymic epithelial cells, was kindly provided by Dr. K. Hirokawa (Tokyo Metropolitan Institute of Gerontology).

\section{Blocking test}

TR were separated into free lymphoid cells (thymic rosette lymphocytes, TRL) and stromal cells by gently pipetting them in phosphate buffered saline (PBS) at $37^{\circ} \mathrm{C}$. The blocking test was then performed as described previously (Nonoyama et al. 1989). Briefly, the separated cells were cultured in hanging drop in $20 \mu 1$ of RPMI 1640 medium sup- 
plemented with $10 \%$ FCS for $10 \mathrm{~min}$ at $37^{\circ} \mathrm{C}$. Binding between TRL and stromal cells were reconstituted during this culture. The blocking test was performed by adding various kind of mAbs into the hanging drop culture. MAbs used are as follows: anti-CD11a (Sanbio, Uden, The Netherlands), Anti-CD2 (Coulter, Hialeah, FL, USA), and anti-TCR $\alpha / \beta$ (Becton Dickinson, Mountain View, CA, USA). The concentration of mAbs were all $1 \mu \mathrm{g}$ / $\mathrm{ml}$. Rosettes which contain more than 3 lymphocytes were counted as positive. The percentage of conjugate forming cells was calculated as :

(The number of reconstituted TR/The number of original TR) $\times 100$

\section{RESUlts}

\section{Isolation of human thymic rosettes}

Human TR could be isolated by collagenase treatment in a mild culture condition of $4^{\circ} \mathrm{C} 30 \mathrm{~min}$. The condition used for isolation of murine TR, that is treating thymic tissue with collagenase and dispase at $37^{\circ} \mathrm{C}$ for $30 \mathrm{~min}$, was found to destroy human TR. TR were further purified by the $1 \mathrm{G}$ gradient method. After repeating IG gradient method, contaminating lymphocytes which did not form rosettes decreased to be less than $1 \%$ of the entire rosette-forming population. Fig. 1 shows the typical shape of human TR, which consist of a stromal cell in center surrounded by several small lymphocytes.

Surface marker analysis of TRL and stromal cells

The purified TR were then separated into free cells by pipetting them in PBS at $37^{\circ} \mathrm{C}$. They were then collected and analyzed for surface phenotype by flowcytometry (Table 1). The stromal cells were gated out on the flowcytometry

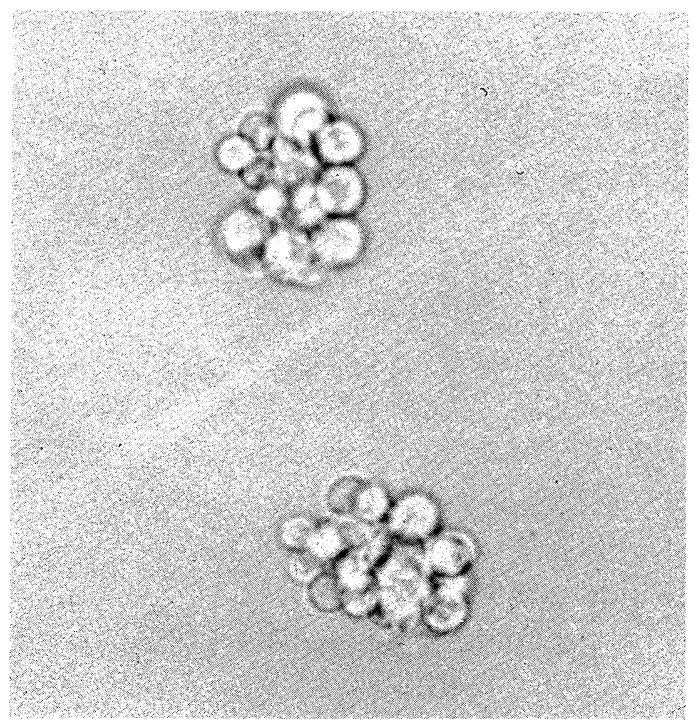

Fig. 1. Human thymic rosettes isolated by collagenase treatment and purified by the $1 \mathrm{G}$ sedimentation method. 
TABLE 1. Cell surface phenotypes of thymic rosette forming lymphocytes (TRL) and unselected thymocytes (UST)

\begin{tabular}{|c|c|c|c|c|}
\hline & $\mathrm{CD} 4-\mathrm{CD} 8-$ & $\mathrm{CD} 4+\mathrm{CD} 8+$ & $\mathrm{CD} 4+\mathrm{CD} 8-$ & $\mathrm{CD} 4-\mathrm{CD} 8+$ \\
\hline TRL & $0.3 \pm 0.2^{\mathrm{a}} 7^{*}$ & $90.4 \pm 3.87^{*}$ & $5.6 \pm 2.77^{*}$ & $2.9 \pm 1.4$ \\
\hline UST & $1.4 \pm 0.5$ & $80.8 \pm 6.2$ & $11.9 \pm 3.0\rfloor$ & $5.5 \pm 2.5$ \\
\hline & $\mathrm{CD} 1+$ & CD3 bright+ & $\mathrm{HLA}-\mathrm{DR}+$ & Tal+ \\
\hline TRL & $93.7 \pm 5.8\urcorner^{*}$ & $4.0 \pm 2.3\urcorner^{*}$ & $58.5 \pm 10.67^{*}$ & $87.0 \pm 3.6\urcorner^{*}$ \\
\hline UST & $75.6 \pm 8.8$ & $19.8 \pm 5.6$ & $32.7 \pm 11.9\rfloor$ & $74.0 \pm 5.5]$ \\
\hline
\end{tabular}

${ }^{a}$ The data are shown as a mean $(\%) \pm$ S.D. of seven independent experiments. ${ }^{*} p<0.05$.

TABLE 2. Surface phenotypes of stromal cells in $T R$

\begin{tabular}{lccccc}
\hline & \multicolumn{6}{c}{ Antibody } \\
\cline { 2 - 6 } & My4 & Mo1 & B1 & UH-1 & Mouse IgG \\
\hline Stromal cells in TR $_{\text {Monocytes }^{\mathrm{a}}}$ & + & + & - & - & - \\
\hline
\end{tabular}

${ }^{a}$ Monocytes were purified from human PBMC by adhesion to plastic wall.

scattergram to analyze only lymphocytes. As shown in Table 1, the majority of TR forming lymphocytes (TRL) were CD4+ CD8+ (DP). The percentage of this subset $(90.4 \% \pm 3.8 \%$, mean \pm s.D. $)$ in TRL is significantly higher than that $(80.8 \% \pm 6.2 \%)$ in unselected thymocytes $(p<0.05$, student $t$-test $)$. Most of human TRL also expressed CD1, which recognize cortical thymocytes. The percentage of CD1 positive cells in TRL was significantly higher than that observed in unselected thymocytes $(p<0.05)$. In contrast, CD3 bright + subset in TRL was only $4.0 \%$, which was significantly less than that in unselected thymocytes. These results indicate that TRL are mainly in an intermediate maturational stage.

HLA-DR is an activation marker for $\mathrm{T}$ cells ( $\mathrm{Yu}$ et al. 1980). The percentage of HLA-DR + cells in TRL $(58.5 \% \pm 10.6 \%)$ is significantly higher than that in unselected thymocytes $(32.7 \% \pm 11.9 \%)(p<0.05)$. Another activation marker, Ta1 (CD26) (Fox et al. 1984) was also highly expressed in TRL. The percentage of Tal + cells in TRL $(87.0 \% \pm 3.6 \%)$ is again significantly higher than that in unselected thymocytes $(74.0 \% \pm 5.5 \%)(p<0.05)$. The typical results of HLADR and Tal expression are shown in Fig. 2.

Surface marker expression on stromal cells in TR was examined using mAb and immunomagnetic beads. Stromal cells were positive for CD14, CD11b but negative for CD20 and UH-l, specific for human thymic epithelial cells. This result indicates that stromal cells in TR were macrophage/dendritic cell origin. 

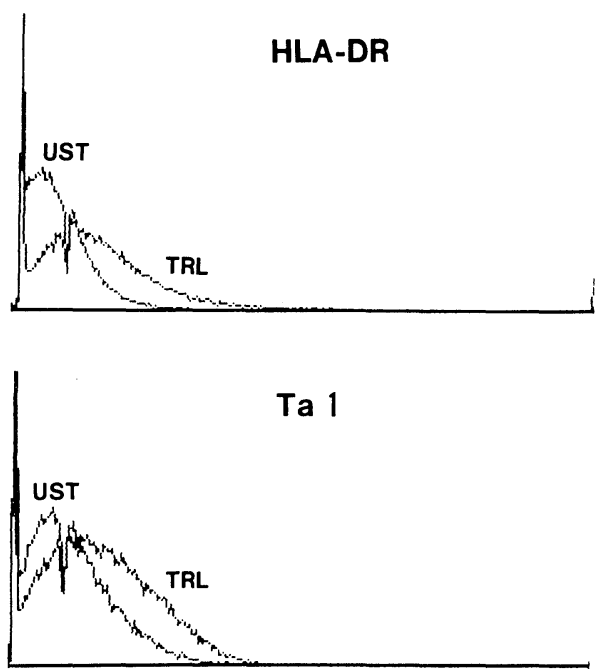

Fig. 2. The expression of HLA-DR and Tal on thymic rosette forming lymphocytes (TRL) and unselected thymocytes (UST). X-axis, fluorescence intensity; $y$-axis, cell numbers.

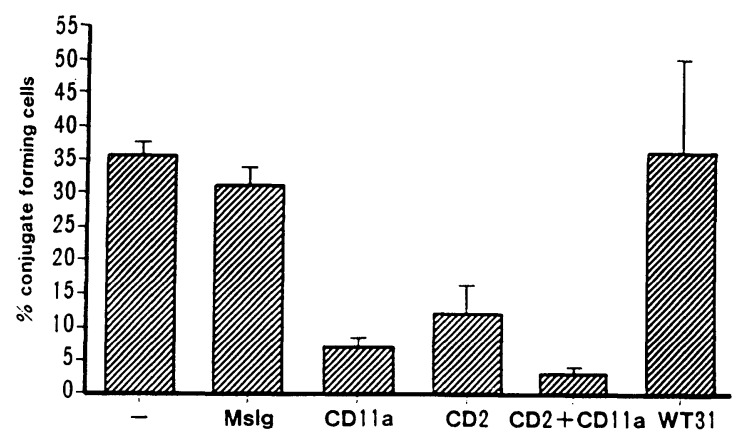

Fig. 3. Results of the blocking test. "\% conjugate forming cells" indicates the percentage of conjugate forming cells after reconstitution of thymic rosettes in vitro.

\section{Blocking test}

The results of the blocking test are shown in Fig. 3. TR were first separated into free thymocytes and stromal cells by pipetting them in PBS. The contamination of lymphocytes which did not form TR was less than $1 \%$. After the short-time culture in hanging drop system (upside down), TRL bound to stromal cells and formed rosettes again. This reconstitution of TR was partially inhibited by either anti-CD2 $\mathrm{mAb}$ or anti-CD11a $\mathrm{mAb}(p<0.05, t$-test). Almost complete inhibition was achieved by the combination of anti-CD2-mAb and 
anti-CD1la mAb. Anti-TCR $\alpha / \beta \mathrm{mAb}$ did not affect the binding in this system.

\section{DisCUSSION}

This report demonstrates that the TR, a cell-cell complex of thymocytes and stromal cell, is present in human thymus as in murine thymus. Modifying the method used for the isolation of murine TR, human TR was successfully isolated. The morphology of human TR is similar to that of murine TR (Kyewski et al. 1982), which consists of a stromal cell surrounded by several lymphocytes. A possibility that human $\mathrm{TR}$ is formed during the preparation process remains. However, the observation by Kyewski and co-workers that thymocytes of each TR were either Thy1.1 or Thy1.2 even if Thyl.1 thymus and Thyl.2 thymus were co-digested to isolate TR (Kyewski et al. 1982) suggests that TR preexist in vivo and were not formed during isolation.

Cell surface phenotyping indicated that $90 \%$ of TRL were CD4+CD8+ (double positive) cells, while $80 \%$ of unselected thymocytes were CD4+CD8+. Significantly lower percentage of TRL were double negative (immature) cells or single positive (mature) cells $(p<0.05)$. The results using anti-CD3 and anti$\mathrm{CD} 1 \mathrm{mAb}$ were consistent with this observation. Significantly higher percentage of TRL expressed CD1+, which reacts with cortical thymocytes, than unselected thymocytes. Mature CD3 bright+cells were rarely found in TRL. This result shows the similarity of human TRL to murine TRL, which co-express CD4 and CD8, and have low density $\mathrm{T}$ cell receptor. It is suggested that TRL are in intermediate stage between intrathymic precursor cells and mature medullarytype thymocytes.

We previously reported that binding to thymic epithelial cells is limited to the thymocytes in an intermediate stage (Nonoyama et al. 1989). Since the stromal cells in TR are macrophage/dendritic cells (Kyewski et al. 1987), the present study demonstrates that the binding of thymocytes to macrophage/dendritic cells also occurs in an intermediate maturation stage. These results indicate that thymocytes in intermediate stage have high affinity to two types of thymic stromal cells, which are thymic epithelial cells and macrophage/dendritic cells.

TRL expressed activation antigens, HLA-DR and Ta1, in a significantly higher percentage than unseparated thymocytes. This higher HLA-DR expression is not due to the difference of maturation stage between TRL and UST, since the expression of HLA-DR on DP cells is less than that on the other stage of thymocytes (Nonoyama 1989). This result is consistent with the observation that murine TRL are activated and express activation markers (Kyewski et al. 1984). Since macrophage/dendritic cells activate peripheral $\mathrm{T}$ cells after making cell complexes in vitro (Langhoff and Steinman 1989), it is likely that macrophage/ dendritic cells in TR cause activation of the TRL.

CD11a ( $\alpha$ chain of LFA-1) and CD2 molecules were determined to be the 
adhesion molecules used for the formation of TR. These two molecules are also known to be the adhesion molecules for the binding of thymocytes and thymic epithelial cells (Denning et al. 1987 ; Nonoyama et al. 1989). The data presented here further confirm the importance of CD11a and CD2 for the interaction of thymocytes and stromal cells. In addition, since these adhesion molecules are also known to conduct an activation signal into cells (Denning et al. 1987; Noesel et al. 1988), it is possible that these molecules play some roles in the activation of TRL.

These findings demonstrate the interaction of $\mathrm{T}$ cells and stromal cells in thymus. Distinct phenotype of TRL suggests that interaction between thymic T cells and stromal cells occurs in a particular stage of $\mathrm{T}$ cells differentiation.

\section{References}

1) Denning, S.M., Tuck, D.T., Vollger, L.W., Springer, T.A., Singer, K.H. \& Haynes, B.F. (1987) Monoclonal antibodies to CD2 and lymphocyte function-associated antigen 3 inhibit human thymic epithelial cell-derived mature thymocyte activation. J. Immunol., 139, 2573-2578.

2) Fox, D.A., Hussey, R.E., Fitzgerald, K.A., Acuto, O., Poole, C., Palley, L., Daley, J.F., Schlossman, S.F. \& Reinherz, E.L. (1984) Ta-1, a novel $105 \mathrm{kd}$ human activation antigen defined by a monoclonal antibody. J. Immunol., 133, 1250-1254.

3) Kyewski, B.A., Rouse, R.V. \& Kaplan, A.S. (1982) Thymocyte rosettes : Multicellular complexes of lymphocytes and bone marrow-derived stromal cells in the mouse thymus. Proc. Natl. Acad. Sci. USA, 79, 5646-5649.

4) Kyewski, B.A., Travis, M. \& Kaplan, H.S. (1984) Intrathymic lymphopoiesis : Stromal cell-associated proliferation of $\mathrm{T}$ cells is independent of lymphocyte genotype. J. Immunol., 133, 1111-1116.

5) Kyewski, B.A., Momburg, F. \& Schirrmacher, V. (1987) Phenotype of stromal cell-associated thymocytes in situ is compatible with selection of $\mathrm{T}$ cell repertoire at an "immature" stage of thymic T cell differentiation. Eur. J. Immunol., 17, 961-966.

6) Langhoff, E. \& Steinman, R.M. (1989) Clonal expansion of human T lymphocytes initiated by dendritic cells. J. Exp. Med., 169, 315-320.

7) Le, P.T., Tuck, D.T., Dinarello, C.A., Haynes, B.F. \& Singer, K.H. (1987) Human thymic epithelial cells produce interleukin-1. J. Immunol., 138, 2520-2526.

8) Lorenz, R.G. \& Allen, P.M. (1989) Thymic cortical epithelial cells can present self-antigens in vivo. Nature, 337, 560-562.

9) Murray, R., Suda, T., Wrighton, M., Lee, F. \& Zlotnik, A. (1989) IL-7 is a growth and maintenance factor for mature and immature thymocyte subsets. Int. Immunol., 1, 526-531.

10) Noesel, C., Miedema, F., Brouwer, M., Rie, M.A., Aarden, L.A. \& Lier, R.A.W. (1988) Regulatory properties of LFA-1 $\alpha$ and $\beta$ chains in human T-lymphocyte activation. Nature, 333, 850-852.

11) Nonoyama, S. (1989) Three color flowcytometry. Jpn. Clin. Immunol., 21, 339348.

12) Nonoyama, S., Nakayama, M., Siohara, T. \& Yata, J. (1989) Only dull CD3+ thymocytes bind to thymic epithelial cells. The binding is elicited by both CD2/ LFA-3 and LFA-1/ICAM-1 interaction. Eur. J. Immunol., 19, 1631-1635.

13) Wekerle, H., Ketelsen, U.-P. \& Ernst, K. (1980) Lymphoepithelial cell complexes in murine thymuses: Morphological and serological characterization. J. Exp. Med., 151, 925-932. 
14) Yu, D.T.Y., Winchester, R.J., Fu, S.M., Gibofsky, A., Ho, H.S. \& Kunkel, H.G. (1980) Peripheral blood Ia-positive T cells. J. Exp. Med., 151, 91-96. 